\title{
Older Women Living Alone in the UK: Does Their Health and Wellbeing Differ from Those Who Cohabit?
}

\author{
Catherine Forward ${ }^{1}$ (D) Hafiz T. A. Khan ${ }^{2}$ (D) Pauline Fox ${ }^{3}$ (D)
}

Received: 26 March 2021 / Accepted: 9 July 2021 / Published online: 8 August 2021

(C) The Author(s), under exclusive licence to Springer Nature B.V. 2021

\begin{abstract}
With an increased prevalence of people living alone in later life, understanding the health and wellbeing of older women living alone in the UK is an important area of research. Little is known about health and wellbeing in this population and whether they differ from those who cohabit. This paper fills this research gap. Analysis was undertaken of Wave 8 of the Understanding Society Household Panel Survey, including variables such as internet use and volunteering. Differences were found between those who live alone and cohabit. Volunteering was a predictor of better health outcomes for those who lived alone but not for those who cohabit, despite similar rates of volunteering. Internet use predicted some better health outcome for those who cohabit but poorer for those who live alone. This suggests lifestyle factors vary in how they affect the health and wellbeing of older women, depending on cohabitation status.
\end{abstract}

Keywords Older women · Lone dwelling · Living alone $\cdot$ Cross-sectional · Volunteering $\cdot$ Internet use

\section{Introduction}

With an ageing global population, understanding predictors of health and wellbeing in later life is becoming increasingly important (World Health Organization, 2015). Health and wellbeing can vary between subgroups within populations and understanding these variations is essential in providing appropriate health and social care resources (British Medical Association, 2016).

Catherine Forward

catherine.forward@kcl.ac.uk

1 College of Nursing, Midwifery and Healthcare, University of West London, England, UK

2 Public Health Group, College of Nursing, Midwifery and Healthcare, University of West London, England, UK

3 The Graduate Centre, University of West London, London, England, UK 


\section{Literature Review}

Health and wellbeing in later life has been shown to have variations between genders (Dwyer et al., 2000; Nagamine et al., 2019). Women experience life course inequalities relating to salary, pensions and lifestyle which all affect the way in which they age (Estes, 2005; Weissman \& Russell, 2018). Significant cultural changes within the UK, reflecting similar changes across Western societies, mean that older women today are ageing in a different context to that of previous generations. Longer life expectancies, increased rates of divorce and increased financial independence have all contributed to the rise of living alone among older women which reflects a pattern seen across the population (Klinenberg, 2014; ONS, 2017). Living alone in later life has been considered a risk factor for poorer health outcomes globally (Desai et al., 2020; Lukaschek et al., 2017; Saito et al., 2017), although evidence regarding the relationship between living arrangements and health and wellbeing remain inconsistent (Fujino \& Matsuda, 2009; Koivunen et al., 2020; Weissman \& Russell, 2018). This paper builds on previous work which indicates that for older women in the UK, there are significant variations in health and wellbeing between those living in differing household compositions (Forward et al., 2021).

Existing literature indicates that lifestyle factors, such as civic engagement, can have different effects depending on individual circumstances in later life (Martinson \& Minkler, 2006). If living alone can be considered a risk factor for social exclusion by the very nature of lone dwelling, then lifestyle factors such as access to transport or engagement in voluntary or care activities might be of more importance to those living alone in their ability to bolster social connectivity (Lucas, 2012; Stanley et al., 2011; Kizony et al., 2020). There is also evidence to suggest that formal social activities such as volunteering or organised groups like to Women's Institute can be used in later life to compensate for a reduction in informal social connections (Ang, 2019). It could, therefore, be theorised that by living alone in later life, one immediate source of social connectivity is lost but that this could be compensated by engaging in formal social activities. This would then suggest that those who live alone may have differing requirements in terms of lifestyle factors in order to promote their health and wellbeing.

Given the recent interest in the role of social connectivity, measures of lifestyle choices which may increase social contact were chosen for this study such as internet use (Kobayashi et al., 2015; Sacker et al., 2017) and transport use (Government Office for Science, 2016; Shergold, 2019). Social contact is often linked with the labour market, but there is also a role for occupation in providing a role or purpose, in addition to any potential financial remuneration (Victor \& Scharf, 2005; Waddell \& Burton, 2006; Schnittker, 2007; Di Gessa et al., 2017). In the last couple of years, there have been significant changes in government policy in order to encourage longer working lives (Department of Work and Pensions, 2017). Therefore, variables which examine the potential role of employment, informal care work outside the home and voluntary work were selected to explore the potential effects of these activities on health in later life. 
Internet use was dichotomised into frequent/infrequent based on previous studies which considered over once a month to be frequent (Cotten et al., 2013). Access to transport can affect ability to access local amenities which has been suggested to have an effect on health and wellbeing (Dwyer et al., 2000; Walker $\&$ Hiller, 2007). Use of car, bus and train transport was included, dichotomised into frequent/infrequent following previous studies (Chng et al., 2016; Hutchinson et al., 2014). Volunteering, caring for someone external to the household and the presence of a non-coresident partner were all dichotomous with yes/no responses.

The quality or suitability of housing and satisfaction with or type of neighbourhood have both been indicated in other studies to affect wellbeing (MacIntyre et al., 2003). Dissatisfaction with either housing or neighbourhood could present as a stressor which would negatively impact on health (Barry et al., 2018) whether this is related to the quality or upkeep of the housing, proximity to kin or access to amenities (Tomaszewski, 2013; Shim et al., 2018). This was broadly represented for this study using a proxy variable 'would like to move' (Eshbaugh, 2009; Lim \& Ng, 2010; Victor \& Scharf, 2005). The response to this dichotomous variable was based on the question "If you could choose, would you stay here in your present home or would you prefer to move somewhere else?" While this is not sensitive to the reasons behind wanting to move, it indicates a dissatisfaction with present housing or neighbourhood which could potentially impact on health and wellbeing. Another aspect of place in later life is the discrepancies between outcomes in rural and urban areas. Existing literature suggests differences in the experience and quality of ageing between urban and rural dwellers. This includes differences in the access to services or infrastructure and differences in social connectivity (Hutchinson et al., 2014; Purtle et al., 2019; Shergold 2019). If living alone can be theorised to present different challenges to social connectivity to cohabiting, then the variation in access to resources in rural versus urban areas are an area worth considering. There is a well-established literature on ageing-inplace and the importance of place in shaping how we age (Toma et al., 2015; Gibney et al., 2020; Shim et al. 2018). As more recent models of healthy ageing are placed in a community context (as opposed to institutional care), the interest as to the nature and quality of this context is increasing (Gileard and Higgs, 2005).

Finally, immigration status to the UK was included as a dichotomous variable. The role of immigration status in determining health and wellbeing is complex and underexplored. Previous evidence indicates there may be variations in the likelihood of those from migrant backgrounds to live alone, and variations in the influence of immigration on health often linked with the disparate migration histories such as the reason for moving to a new country or the country of birth (Jayaweera, 2014; Lee and Edmonston, 2019).

The health and wellbeing of older women who live alone is of interest to researchers and policymakers alike. A better understanding of the nature and predictors of health and wellbeing in this population will enable policies to promote more appropriate and cost-effective interventions. There is currently little evidence regarding the health and wellbeing of this population particularly comparing it to that of those who cohabit (Forward et al., 2020). This paper fills a 
research gap by presenting analysis of the Understanding Society dataset at the Institute for Social and Economic Research.

\section{Research Design}

\section{Data}

Data for this study were taken from the Understanding Society dataset held by the UK Data Service. Wave 8 of the data was used which was the most recently released at the time of analysis, this was collected between January 2016 and June 2018 and made available in November 2018. Further information on the use and availability of the data is available elsewhere (Knies, 2018). The data were refined to include only those women who were over the age of $65(N=4279)$ and were dichotomised into those living alone $(N=1852)$ and those living with others $(N=2427)$ as per similar studies (Kharicha et al., 2007; Zali et al., 2017). The total sample included in the analysis was $N=4279$, with those living alone. Weighting was applied to the dataset as per published guidance (Knies, 2018).

\section{Justification of the Choice of Variables}

The demographic variables used such as age and education are commonly used in such studies as control variables given their acknowledged relationship with health and wellbeing. Immigration is also included as a demographic variable for the reasons discussed above. This study sought to explore the role of more novel variables representing time use or lifestyle and were chosen based on findings from previous studies which indicated the potential role of certain social and lifestyle factors in determining health and wellbeing. Variables included having volunteering in the last year, frequency of transport use (car, bus and train), a desire to move (as a proxy for dissatisfaction with housing or neighbourhood), going out socially, seeing friends and family, regular internet use.

The outcome variables were chosen from the available data, based on previous studies (Ocean et al., 2018; Tang et al., 2017; Weissman \& Russell, 2018). As health and wellbeing are such multifaceted concepts, seven outcome variables were chosen with the aim of covering a range of concepts. The Short-Form 12 health assessment (Ware et al., 1998), both the physical (SF-12 PCS) and the mental (SF-12 MCS) component scores were used as was the General Health Questionnaire score (GHQ-Goldberg, 1972), all of which were scale variables based on standardised health outcome measures used in clinical practice. The SF-12 MCS and PCS measure mental and physical functioning respectively. The reversed GHQ score was used as a measure of subjective wellbeing with a higher score indicating better wellbeing as per previous studies (Ocean et al., 2018). Dichotomous outcome variables were also used. Presence of a long-term health condition or disability (yes/no) is an objective measure of a diagnosis, distinct 
from the subjective measure of self-rated health (good/poor) but each measure an aspect of health and wellbeing worth considering. Frequent health service use can indicate poorer health or wellbeing for various reasons and also reflects burden on local services (yes/no). Finally, life satisfaction reflects a eudaemonic aspect of wellbeing (satisfied/not satisfied) (Qu and Weston, 2003).

\section{Data Analysis Strategy}

Descriptive statistics examined patterns and trends in the demographics of older women who live alone or who cohabit. Tests of association explored the variations between the two groups. These were followed by regression analyses of the demographic and lifestyle predictor variables on the seven health and wellbeing outcome variables. Binary logistic regressions were used for those categorical variables which were dichotomised (self-rated health, health service use, life satisfaction and presence of a long-term condition or disability). Linear regressions were carried out for the scale outcome variables (SF-12 MCS and PCS and the GHQ (reversed score)). Regressions were carried out on the subset of data containing women who live alone initially, then on those who cohabit.

\section{Results}

\section{Descriptive Statistics}

Table 1 displays the descriptive statistics in a crosstabulation of the household status groups by the predictor variables. As can be seen, those who lived alone tended to be older than those who cohabit which was found to be statistically significant $\left(\chi^{2}\right.$ $396.40, p \leq 0.001)$. They were also less likely to be in employment or own their own homes $\left(\chi^{2} 20.99, p \leq 0.001\right.$ and $\chi^{2} 163.66, p \leq 0.001$, respectively). Car use was by far the most common mode of transport for both groups with $87.9 \%$ of the total subsample indicating frequent car use. Public transport was far lower for all groups with train use being the least frequent. Roughly $5 \%$ of all groups identified as immigrant to the UK which is consistent with other data sources showing a lower rate of nonUK born citizens in those aged over 65 than in the 26-64 group (Vargas-Silva \& Rienzo, 2019). The number of 'yes' responses was relatively low at $5 \%$ which could potentially have affected statistical tests. This was also the case with ethnicity. This remains a limitation of the study, highlighting an area for further research beyond this paper.

Those living alone were less likely to want to move than the total sample or than those who cohabit $\left(13.4 \%, 16.1 \%\right.$ and $18 \%$ respectively, $\left.\chi^{2} 17.07, p \leq 0.001\right)$. They were also less likely to volunteer, provide care for someone or use the internet: all of which may be consistent with their higher average age. A slightly higher percentage of those living alone had non-resident partners which is consistent with the cohabiting group largely consisting of those living with partners. 
Table 1 Descriptive statistics by household type

\begin{tabular}{|c|c|c|c|c|c|c|c|c|}
\hline \multirow[t]{2}{*}{ Variable } & \multirow[t]{2}{*}{$\begin{array}{l}\text { Categories/ measure- } \\
\text { ment }\end{array}$} & \multicolumn{2}{|c|}{$\begin{array}{l}\text { Those living } \\
\text { alone }\end{array}$} & \multicolumn{2}{|c|}{$\begin{array}{l}\text { Those living } \\
\text { with others }\end{array}$} & \multicolumn{2}{|c|}{ Total sample } & \multirow[t]{2}{*}{$\chi^{2} /$ f-test } \\
\hline & & $\mathrm{N} / \mathrm{M}$ & $\% / \mathrm{SD}$ & N/M & $\% / \mathrm{SD}$ & N/M & $\% / \mathrm{SD}$ & \\
\hline \multirow[t]{3}{*}{ Age } & $65-74$ & 764 & 41.3 & 1625 & 67.0 & 2389 & 55.8 & \multirow[t]{3}{*}{$396.4 * * *$} \\
\hline & $75-84$ & 669 & 36.9 & 675 & 27.8 & 1344 & 31.5 & \\
\hline & $85+$ & 419 & 22.6 & 127 & 5.2 & 546 & 12.8 & \\
\hline Income (log) & Scale & 7.14 & 0.46 & 7.86 & 0.52 & 7.55 & 0.61 & $2277.18 * * *$ \\
\hline \multirow[t]{2}{*}{ Education } & School level & 1415 & 76.4 & 1826 & 75.2 & 3241 & 75.7 & \multirow[t]{2}{*}{0.78} \\
\hline & Degree + & 437 & 23.6 & 601 & 24.8 & 1038 & 24.4 & \\
\hline \multirow[t]{2}{*}{ Homeowner } & Yes & 1232 & 66.5 & 2024 & 83.4 & 3256 & 76.1 & \multirow[t]{2}{*}{$163.66 * * *$} \\
\hline & No & 620 & 33.5 & 404 & 16.6 & 1024 & 23.9 & \\
\hline \multirow[t]{4}{*}{ UK Region } & England & 1531 & 82.7 & 2066 & 85.1 & 3597 & 84.0 & \multirow[t]{4}{*}{4.81} \\
\hline & Wales & 109 & 5.9 & 117 & 4.8 & 226 & 5.3 & \\
\hline & Scotland & 163 & 8.8 & 188 & 7.7 & 351 & 8.2 & \\
\hline & Northern Ireland & 49 & 2.6 & 57 & 2.3 & 106 & 2.5 & \\
\hline \multirow[t]{2}{*}{ Employed } & Yes & 107 & 5.8 & 233 & 9.6 & 340 & 7.9 & $20.99 * * *$ \\
\hline & No & 1745 & 94.2 & 2194 & 90.4 & 3939 & 92.1 & \multirow{3}{*}{1.42} \\
\hline \multirow[t]{2}{*}{ Ethnicity } & White & 1918 & 98.2 & 2371 & 97.7 & 4190 & 97.9 & \\
\hline & Non-white & 33 & 1.8 & 56 & 2.3 & 89 & 2.1 & \\
\hline \multirow[t]{2}{*}{ Car use } & Frequent & 1482 & 80.2 & 2274 & 93.8 & 3753 & 87.9 & \multirow[t]{2}{*}{183.087 **** } \\
\hline & Infrequent & 366 & 19.8 & 150 & 6.2 & 515 & 12.1 & \\
\hline \multirow[t]{2}{*}{ Bus use } & Frequent & 780 & 42.2 & 808 & 33.3 & 1587 & 37.2 & \multirow[t]{2}{*}{$35.026^{* * * *}$} \\
\hline & Infrequent & 1070 & 57.8 & 1616 & 66.7 & 2683 & 62.8 & \\
\hline \multirow[t]{2}{*}{ Train use } & Frequent & 198 & 10.7 & 278 & 11.5 & 476 & 11.2 & \multirow[t]{2}{*}{0.647} \\
\hline & Infrequent & 1653 & 89.3 & 2144 & 88.5 & 3793 & 88.8 & \\
\hline \multirow[t]{2}{*}{ Immigrant to UK } & Yes & 90 & 4.9 & 124 & 5.1 & 214 & 5.0 & \multirow[t]{2}{*}{0.122} \\
\hline & No & 1749 & 95.1 & 2293 & 94.9 & 4037 & 95.0 & \\
\hline Would like to move & Yes & 248 & 13.4 & 438 & 18.0 & 686 & 16.1 & $17.074 * * *$ \\
\hline & No & 1590 & 85.9 & 1974 & 81.3 & 3559 & 83.3 & \\
\hline Volunteered in last & Yes & 374 & 20.2 & 532 & 21.9 & 906 & 21.2 & 1.932 \\
\hline year & No & 1478 & 79.8 & 1892 & 78.1 & 3365 & 78.8 & \\
\hline Carer (outside of & Yes & 217 & 11.7 & 292 & 12.1 & 508 & 11.9 & 0.107 \\
\hline household) & No & 1634 & 88.3 & 2131 & 87.9 & 3761 & 88.1 & \\
\hline Regular internet use & Yes & 885 & 47.8 & 1596 & 65.8 & 2476 & 58.0 & $140.519 * * *$ \\
\hline & No & 967 & 52.2 & 828 & 34.2 & 1795 & 42.0 & \\
\hline Non-resident partner & Yes & 93 & 5.4 & 8 & 3.3 & 101 & 5.1 & 1.984 \\
\hline & No & 1634 & 94.6 & 237 & 96.7 & 1866 & 94.9 & \\
\hline Sees family/friends & Yes & 1798 & 97.1 & 2289 & 97.2 & 4087 & 96.2 & 0.090 \\
\hline & No & 54 & 2.9 & 65 & 2.8 & 119 & 2.8 & \\
\hline Goes out socially & Yes & 1549 & 83.8 & 2066 & 87.8 & 3615 & 86.0 & $13.705^{* * * *}$ \\
\hline & No & 300 & 16.2 & 288 & 12.2 & 588 & 14.0 & \\
\hline
\end{tabular}

\footnotetext{
${ }^{* * *} p \leq 0.001, * * p \leq 0.01, * p \leq 0.05$
} 
Only a small percentage of all groups reported not seeing their friends or family at least once a month $(2.8-2.9 \%)$, but a higher percentage of those living alone reported not going out socially than those cohabiting $(16.2 \%$ and $12.2 \%$ respectively, $p \leq 0.001)$. This latter result may reflect the higher average age of those living alone which may be associated with reduced mobility or transport access.

\section{Regression Analyses}

Table 2 presents the results from the regressions of the predictor variables on the health and wellbeing outcome variables for the subgroup of women who lived alone. The results of the regressions for those who cohabit are presented in Table 3 .

For those women who live alone, regional variations between the four UK countries were found to be significant predictors in some cases such as GP use and SF-12 MCS (OR 2.19*** $(1.42,3.39)$ and $\beta=1.85^{*}(0.18,3.51)$ respectively) which was not the case for those who cohabit. Homeownership and income tended to be more commonly a predictor of better health for those who cohabit than those who live alone. Interestingly internet use tended to be predictive of better health outcomes for those who cohabit (e.g. SF-12 MCS $\beta=2.63 * * *$ (95\%CI: 1.36, 3.90), SF-12 PCS $\beta=3.06 * * *$ (95\%CI: 1.43, 4.69)) but poorer outcomes in those who live alone (e.g. GHQ $\left.\beta-0.66^{*}(-1.22,-0.10)\right)$.

The most notable finding for those women who live alone was the predictor variable volunteering. For 6 of the 7 regression outcome variables (with the exception being GP use) volunteering was a predictor of better health and wellbeing for women who live alone but not for those who cohabit. Table 3 suggests that there were not significant differences in the rates of volunteering between the household groups.

Another notable finding was the difference in the way in which internet use predicted the health and wellbeing of older women. For those who live alone, frequent internet use predicted poorer life satisfaction and mental health as measured by a reversed GHQ score (OR $0.68 * *(0.51,0.91)$ and $\beta-0.66 *(-1.22,-0.10)$ respectively). However, for those who cohabited, frequent internet use was found to be predictive of better health outcomes in terms of several health outcomes including both SF-12 scores (MCS $\beta 2.63 * * *(1.36,3.90)$ and PCS $\beta 3.06 * * *(1.43,4.69)$ ).

One final area of analysis is that of location, neighbourhood and community. These are represented in the regression analyses by the variables: region; urban/ rural and wanting to move. The findings presented herein indicate variations in the ways in which older women may experience place in later life: either geographical region, home or neighbourhood. The variable 'wanting to move' is not specific as to the reason and so may reflect dissatisfaction with home, community or location but interestingly was never found to be a predictor of health for those living alone. So too with rurality, which was mainly found to be a predictor of better health for those who cohabit (e.g. SF-12 PCS $\beta=1.69 * *(0.61,2.76)$ ). UK regions were only found to be predictive of health outcomes for those living alone and not for those cohabiting. Living in Wales predicted higher health service use 


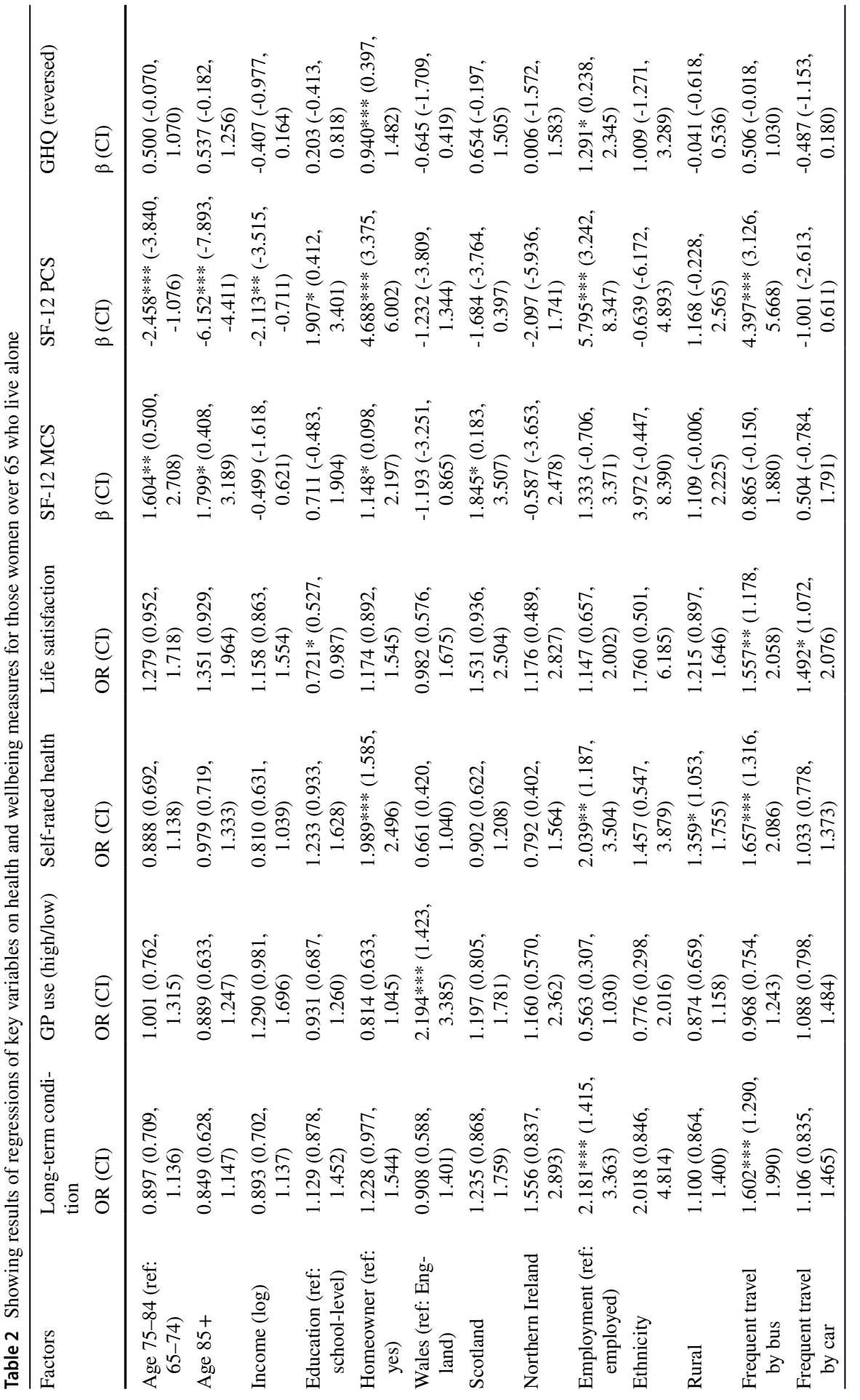




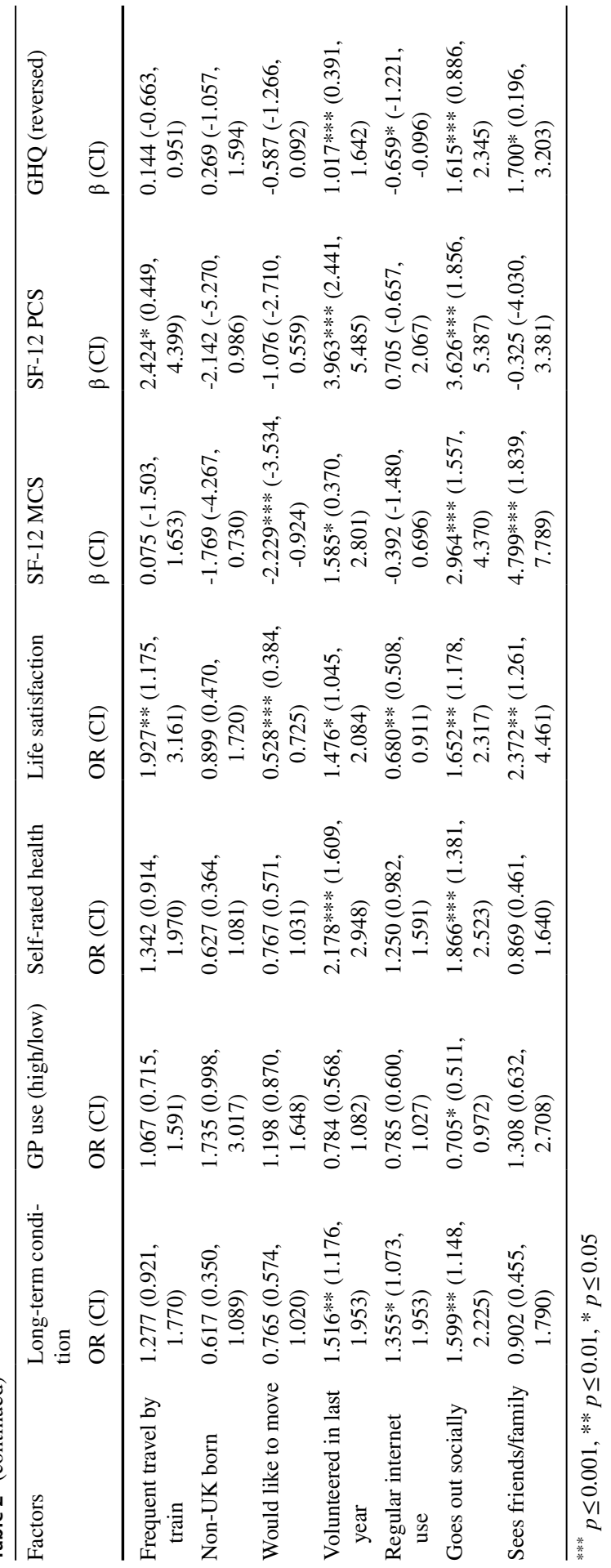




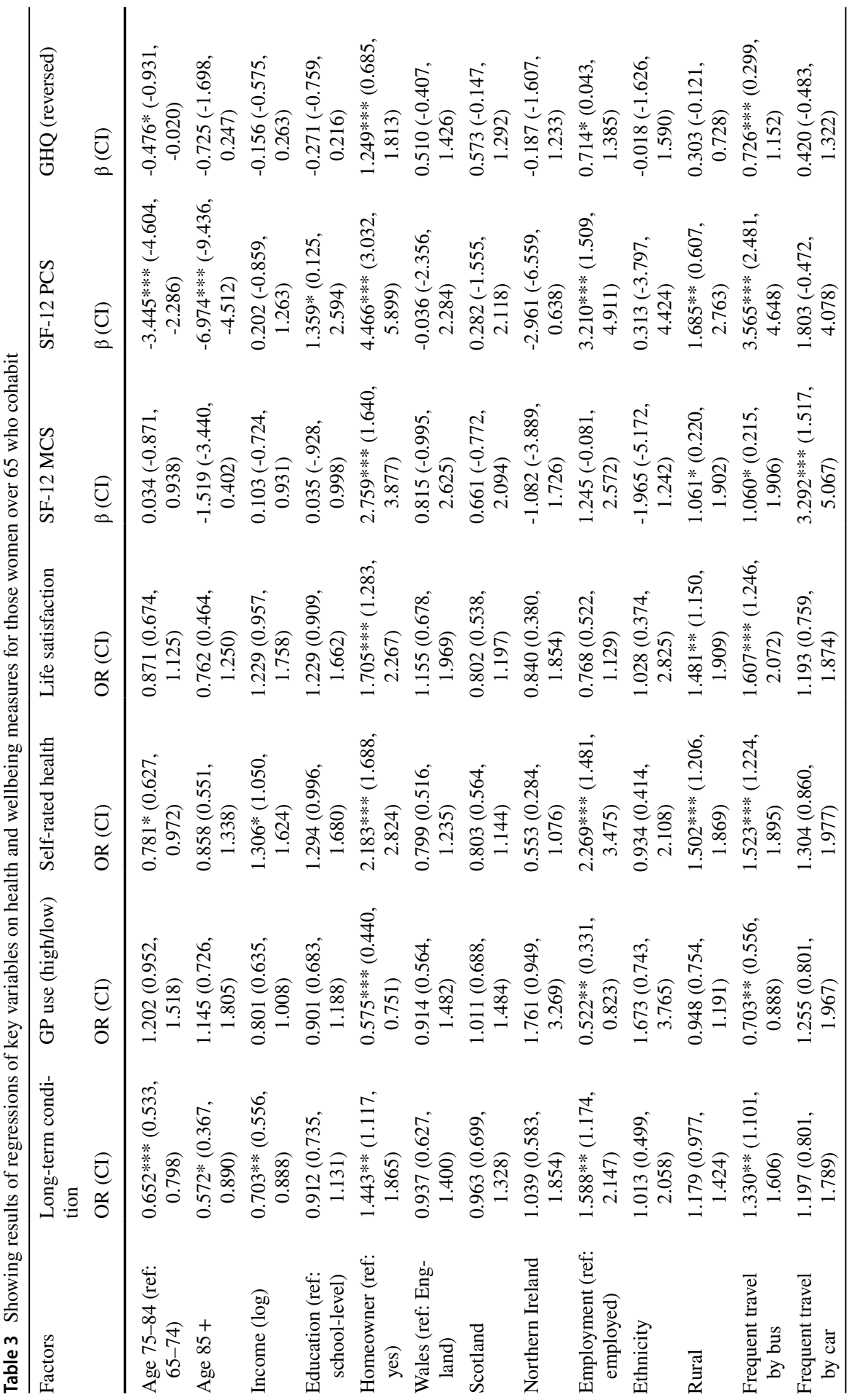




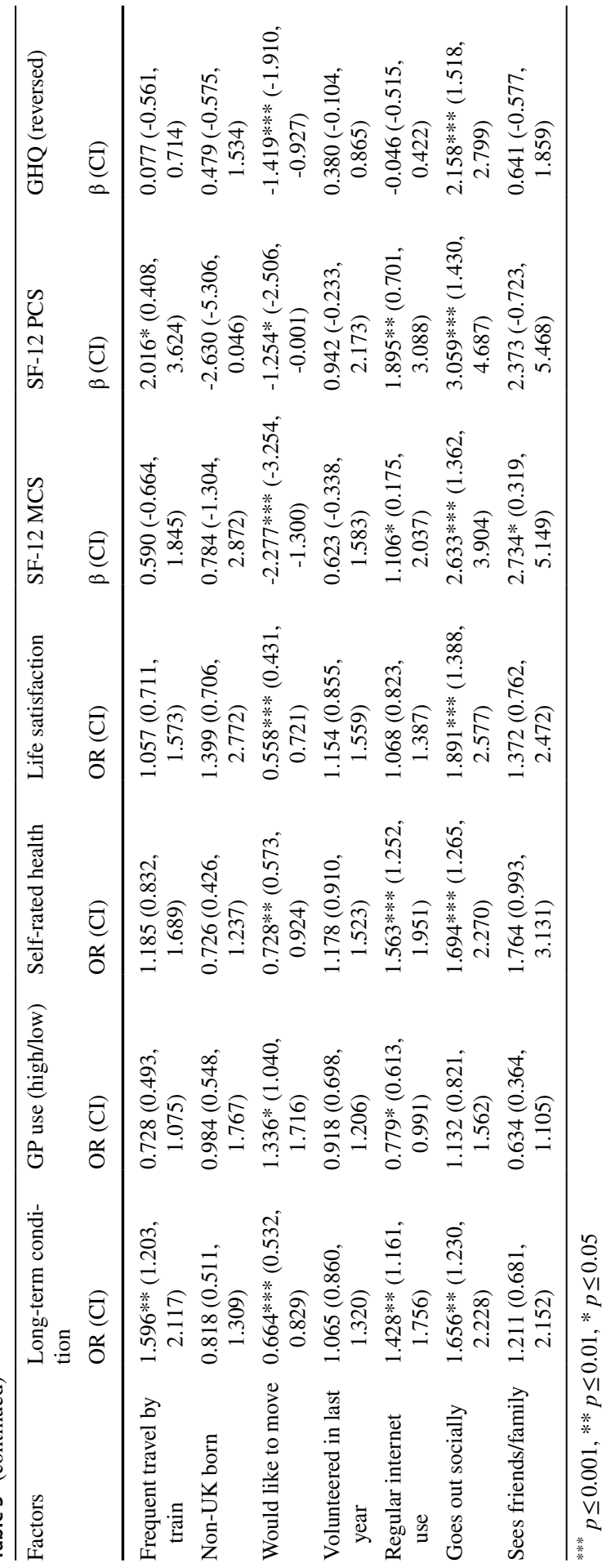


$(\mathrm{OR}=2.19 * * *(1.42,3.39))$ and living in Scotland was found to be predictive of better SF-12 MCS scores $\left(\beta=1.85^{*}(0.18,3.51)\right)$.

\section{Discussion and Conclusion}

The differences in the interaction of SES measures on health and wellbeing between those who live alone and those who cohabit are possibly surprising as it could be hypothesised that for those living alone, higher SES would mitigate any disadvantages of lone dwelling. This does support the idea that women who live alone in later life may foster alternative resources in order to support their health and wellbeing (Walker \& Hiller, 2007). This latter point is further supported in that volunteering was consistently found to predict better health for those who live alone and not for those who cohabit.

\section{Volunteering and Employment}

One of the key findings is the variation in the interaction of volunteering and health and wellbeing between the household groups. This could indicate that those who live alone tend to only volunteer when they are in better health, or it could suggest that the benefits gained from volunteering are more significant for those who live alone. Existing literature points to the benefits of volunteering in later life (Okun et al., 2013; Burr et al., 2011; Nazroo \& Matthews, 2012; Griep et al., 2017) and, as women who live alone may be more susceptible to social isolation, it could be suggested that by engaging in volunteering they are accessing social contact which is often associated with the labour market (Victor \& Scharf, 2005). It may also be that by contributing to community life and the labour force, volunteering may boost selfworth in post-modern society which can devalue life post-retirement (Estes et al., 2003). Finally, it is important to note that there are differences in the health and wellbeing as well as the financial status of those who volunteer. Those who volunteer have been shown to be wealthier and are more likely to be in better health. There are also variations in the uptake of volunteer work which has not been fully explained by external factors such as wealth or health and which may conflate the effect of volunteering on health and wellbeing (Plagnol and Huppert, 2010; Nazroo \& Matthews, 2012). Given the policy drive in the UK which encourages older people to continue working, it is of importance that this area receives further interest from researchers in understanding how a longer working life may impact on health and wellbeing (Department for Work and Pensions, 2017). Further research may also consider differences in the benefits of paid and unpaid work, in addition to barriers and enablers to start and maintain voluntary work. 


\section{Internet Use}

Firstly, it should be acknowledged that the relationship between health and internet use is likely to be reciprocal and complex. For example, those with poorer health may use the internet more to compensate for reduced community mobility, or they may use it less as poorer health may limit access to resources. Good health may enable better access to support with technology and use or it may, for some, negate the need for regular internet use if social or information needs are met elsewhere. The existing evidence has yet to clearly demonstrate the ways in which internet use is related to health and wellbeing in later life (Cotten et al., 2013; Sacker et al., 2017; Walkner et al., 2018). What is particularly interesting for this study is that these results indicate a distinct difference for older women who live alone and are suggestive of important variations in the ways in which one lifestyle element can affect the health and wellbeing of those living alone in a different way to those cohabiting. Consideration should be given too, of the reciprocal nature between technology use and health and wellbeing in this specific context. Older women who live alone may use the internet for different purposes to their cohabiting peers which would impact differently on their wellbeing. For example, using the internet for leisure activities has been shown to differ from use for interpersonal communication or task performance in terms of influence on wellbeing (Lifshitz et al., 2018). While some studies have shown internet use to improve social connectivity, this can vary depending on the type of interaction and normative comparisons amongst peers (Gracia and Herrero, 2009; Forsman and Nordmyr, 2017). Further research could consider aspects such as support to access internet resources including assessments of the effects of digital poverty. The internet as a resource becomes of increasing importance as more services move online and events such as the Covid-19 pandemic indicate growing reliance on the internet to provide essential services.

\section{Location, Neighbourhood, Community}

The results examining the interaction between place and ageing support existing evidence which points to the importance of the 'place' when ageing-in place, whether this be the home, neighbourhood or UK region. Inequalities between and within the four UK regions are already recognised in the literature as a result of local economies, funding variations and the devolution of national government powers to local governments (Timmins, 2013). The variations in outcomes seen in this analysis suggest that those who live alone have different needs to those who cohabit and are therefore more vulnerable to variations or gaps in service provision (Bevan et al., 2014). However, the complex interplay of factors affecting the health and wellbeing of older women requires further research to understand how women who live alone can be best supported into later life within the context of their home and communities. While varying needs of individuals need considering, these results also reflect wider patterns of health inequities across the UK regions (Public Health England, 2018). Policy and service provision should strive to ensure that it allows for regional 
variations in terms of health needs while aiming to minimise inequities between areas.

This paper is the first to examine differences in predictors of health and wellbeing between women who live alone and those who cohabit. It presents findings from cross-sectional analysis which examines general patterns and trends within the two subgroups before discussing the results of regression analyses. Similarities and differences were demonstrated between the two groups which point to varying needs in later life and thus has implications for policy and practice.

These all point towards key variations in the ways in which the health and wellbeing of older women can vary by household composition. Further research is required to understand the mechanisms involved and the variations in lived experience, but these findings are supportive of approaches to later life which acknowledge the variations in the ways which variables can accumulate to affect health and wellbeing.

Key areas of interest were highlighted such as the roles of volunteering, internet use and regional or neighbourhood factors. Areas for further research include expanding the knowledge regarding the role volunteering plays in promoting health and wellbeing, and how this might vary between population sub-groups. As technology plays an increasingly important role in later life, the relationship between technology (e.g. the internet) and health and wellbeing requires further exploration, especially in relation to digital poverty.

Limitations of the study which require acknowledging include the cross-sectional nature of the analysis which limits the inferences regarding the cause and effect of determinants of health. Cross-sectional analysis was chosen as this forms part of a larger project examining the current state of the health and wellbeing of older women living in the UK. Other limitations include the relative low numbers of people identifying as non-white and non-UK born which may affect the sensitivity of the statistical analysis. These both point to areas for further research in addition to those already highlighted. As with all quantitative research, the ability of this data to provide an insight into more nuanced aspects of living alone is also limited: this points to the importance of further research examining the qualitative aspects of this phenomenon.

This paper is the first to examine in detail the variations in predictors of health and wellbeing between women who live alone and those who cohabit in the UK. It indicates that predictors of health do vary by household composition and suggests that policy needs to accommodate this. By adding to the evidence regarding determinants of health in later life, this paper contributes to the growing literature which indicates the importance of understanding variations in subgroups of populations. By understanding these variations, policy and practice can adapt and ensure that appropriate resources are provided in order to promote better health and wellbeing outcomes in later life and ensure community services are cost-effective.

Funding This study was completed as part of a $\mathrm{PhD}$ project, funded by the University of West London (Sponsor Licence No: VJVD7MND6).

Older women living alone in the UK: does their health and wellbeing differ from those who cohabit? 


\section{References}

Ang, S. (2019). Life course social connectedness: Age-cohort trends in social participation. Advances in Life Course Research, 39, 13-22.

Barry, A., Heale, R., Pilon, R., \& Lavoie, A. M. (2018). The meaning of home for ageing women living alone: an evolutionary concept analysis. Health \& Social Care in the Community, 26(3), e337-e344.

Bevan, G., Karanikolos, M., Exley, J., Nolte, E., Connolly, S. and Mays, N., 2014. The four health systems of the United Kingdom: How do they compare? Summary Report.

British Medical Association. (2016). Growing Older in the UK. British Medical Association.

Burr, J. A., Tavares, J., \& Mutchler, J. E. (2011). Volunteering and Hypertension Risk in Later Life. Journal of Aging and Health, 23(1), 24-51.

Chng, S., White, M., Abraham, C., \& Skippon, S. (2016). Commuting and wellbeing in London: The roles of commute mode and local public transport connectivity. Preventive Medicine, 88, 182-188.

Cotten, S. R., Anderson, W. A., \& Mccullough, B. M. (2013). Impact of internet use on loneliness and contact with others among older adults: Cross-sectional analysis. Journal of Medical Internet Research, $15(2), 39$.

Department of Work and Pensions. (2017). Fuller Working Lives. A Partnership Approach. DWP.

Desai, R., John, A., Stott, J., \& Charlesworth, G. (2020). Living alone and risk of dementia: A systematic review and meta-analysis. Ageing Research Reviews, 101122.

Di Gessa, G., Corna, L. M., Platts, L. G., Worts, D., McDonough, P., Sacker, A., \& Glaser, K. (2017). Is being in paid work beyond state pension age beneficial for health? Evidence from England using a lifecourse approach. Journal of Epidemiol Community Health, 71(5), 431-438.

Dwyer, M., Gray, A., \& Renwick, M. (2000). Factors Affecting the Ability of Older People to Live Independently: A Report for the International Year of the Older Persons. Ministry of Social Policy.

Eshbaugh, E. M. (2009). The role of friends in predicting loneliness among older women living alone. Journal of Gerontological Nursing, 35(5), 13-16.

Estes, C. (2005). Women, Ageing and Inequality: A Feminist Perspective. In V. L. Bengtson, P. Coleman, \& T. Kirkwood (Eds.), Handbook of Age and Ageing (1st ed., pp. 552-559). Cambridge University Press.

Estes, C. L., Biggs, S., \& Phillipson, C. (2003). Social theory, social policy and ageing: A critical introduction (1st ed.). Open University Press.

Forsman, A. K., \& Nordmyr, J. (2017). Psychosocial links between Internet use and mental health in later life: A systematic review of quantitative and qualitative evidence. Journal of Applied Gerontology, 36(12), 1471-1518.

Forward, C., Khan, H. and Fox, P. (2020). The health and well-being of older women living alone in the United Kingdom and beyond: a scoping review. Journal of Women \& Aging, 1-14

Forward, C., Khan, H. T., Fox, P., \& Usher, L. (2021). The health and wellbeing of older women living alone in the UK: is living alone a risk factor for poorer health? Ageing International.

Fujino, Y., \& Matsuda, S. (2009). Prospective study of living arrangement by the ability to receive informal care and survival among Japanese elderly. Preventive Medicine, 48(1), 79-85.

Gibney, S., Zhang, M., \& Brennan, C. (2020). Age-friendly environments and psychosocial wellbeing: A study of older urban residents in Ireland. Aging \& Mental Health, 24(12), 2022-2033

Gilleard, C., \& Higgs, P. (2005). Contexts of ageing: Class, cohort and community. Polity.

Goldberg, D.P. (1972). The detection of psychiatric illness by questionnaire; a technique for the identification and assessment of non-psychotic psychiatric illness. England; United Kingdom.

Government office for Science. (2016). Future of an Aging Population. Government Office for Science.

Gracia, E., \& Herrero, J. (2009). Internet use and self-rated health among older people: a national survey. Journal of Medical Internet Research, 11(4), e49.

Griep, Y., Hanson, L. M., Vantilborgh, T., Janssens, L., Jones, S. K., \& Hyde, M. (2017). Stockholms Universitet, Samhällsvetenskapliga Fakulteten and Stressforskningsinstitutet, Can volunteering in later life reduce the risk of dementia? A 5-year longitudinal study among volunteering and non-volunteering retired seniors. Plos One, 12(3), e0173885.

Hutchinson, J., White, P. C., \& Graham, H. (2014). Differences in the social patterning of active travel between urban and rural populations: Findings from a large UK household survey. International Journal of Public Health, 59(6), 993-998.

Jayaweera, H. (2014). Health of migrants in the UK: What do we know. The Migration Observatory.

Kharicha, K., Iliffe, S., Harari, D., Swift, C., Gillmann, G., \& Stuck, A. E. (2007). Health risk appraisal in older people 1: Are older people living alone an "at-risk" group? British Journal of General Practice, 57(537), 271-276. 
Kizony, R., Schreuer, N., Rotenberg, S., Shach-Pinsly, D., Sinoff, G., \& Plaut, P. (2020). Participation in outof-home activities among older adults: the role of mobility, attitudes and travel behaviors. Journal of Transport \& Health, 17, 100846.

Klinenberg, E. (2014). Going Solo: The Extraordinary Rise and Surprising Appeal of Living Alone (2nd ed.). Gerald Duckworth \& Co.

Knies, G. (2018). Understanding society-the UK household longitudinal study: Waves 1-8, user manual. University of Essex.

Kobayashi, L. C., Wardle, J., \& Wagner, C. V. (2015). Internet use, social engagement and health literacy decline during ageing in a longitudinal cohort of older English adults. Journal of Epidemiology and Community Health, 69(3), 278-283.

Koivunen, K., Sillanpää, E., von Bonsdorff, M., Sakari, R., Pynnönen, K., \& Rantanen, T. (2020). Living alone vs. living with someone as a predictor of mortality after a bone fracture in older age. Aging Clinical and Experimental Research, 32(9), 1697.

Lee, S. M., \& Edmonston, B. (2019). Living alone among older adults in Canada and the US. In Healthcare (Vol. 7, No. 2, p. 68). Multidisciplinary Digital Publishing Institute.

Lifshitz, R., Nimrod, G., \& Bachner, Y. G. (2018). Internet use and well-being in later life: a functional approach. Aging \& Mental Health, 22(1), 85-91.

Lim, L. L., \& Ng, T. P. (2010). Living alone, lack of a confidant and psychological well-being of elderly women in Singapore: The mediating role of loneliness. Asia-Pacific Psychiatry, 2(1), 33-40.

Lucas, K. (2012). Transport and social exclusion: Where are we now?. Transport Policy, 20, 105-113.

Lukaschek, K., Vanajan, A., Johar, H., Weiland, N., \& Ladwig, K. (2017). "In the mood for ageing": Determinants of subjective well-being in older men and women of the population-based KORA-Age study. BMC Geriatrics, 17(1), 1-9.

Macintyre, S., Ellaway, A., Hiscock, R., Kearns, A., Der, G., \& McKay, L. (2003). What features of the home and the area might help to explain observed relationships between housing tenure and health? Evidence from the west of Scotland. Health \& Place, 9(3), 207-218.

Martinson, M., \& Minkler, M. (2006). Civic engagement and older adults: A critical perspective. The Gerontologist, 46(3), 318-324.

Nagamine, Y., Fujiwara, T., Tani, Y., Murayama, H., Tabuchi, T., Kondo, K. and Kawachi, I. (2019). Gender difference in the association between subjective socioeconomic mobility across life course and mortality at older ages: Results from the JAGES longitudinal study. Journal of Epidemiology. JE20190083

Nagamine, Y., Fujiwara, T., Tani, Y., Murayama, H., Tabuchi, T., Kondo, K., \& Kawachi, I. (2019). Gender Difference in the Association Between Subjective Socioeconomic Mobility Across Life Course and Mortality at Older Ages: Results From the JAGES Longitudinal Study. Journal of Epidemiology, JE20190083.

Nazroo, J., \& Matthews, K. (2012). The impact of volunteering on well-being in later life. WRVS.

Ocean, N., Howley, P., \& Ensor, J. (2018). Lettuce be happy: A longitudinal UK study on the relationship between fruit and vegetable consumption and well-being. Social Science \& Medicine, 222, 335-345.

Office for National Statistics, \& (ONS). (2017). Families and households. Palgrave Macmillan, a Division of Macmillan Publishers Ltd.

Okun, M. A., Yeung, E. W., \& Brown, S. (2013). Volunteering by Older Adults and Risk of Mortality: A Meta-Analysis. Psychology and Aging, 28(2), 564-577.

Plagnol, A. C., \& Huppert, F. A. (2010). Happy to Help? Exploring the Factors Associated with Variations in Rates of Volunteering Across Europe. Social Indicators Research, 97(2), 157-176.

Public Health England (2018). Health profile for England: 2018. PHE: London.

Purtle, J., Nelson, K. L., Yang, Y., Langellier, B., Stankov, I., \& Roux, A. V. D. (2019). Urban-rural differences in older adult depression: A systematic review and meta-analysis of comparative studies. American Journal of Preventive Medicine, 56(4), 603-613.

Qu, L., \& Weston, R. (2003). Family Trends: Ageing, Living Arrangements and Subjective Wellbeing. Family Matters, (66), 26-33.

Sacker, A., Ross, A., Macleod, C. A., Netuveli, G., \& Windle, G. (2017). Health and social exclusion in older age: Evidence from Understanding Society, the UK household longitudinal study. J Epidemiology Community Health, 71(7), 681-690.

Saito, T., Murata, C., Aida, J., \& Kondo, K. (2017). Cohort study on living arrangements of older men and women and risk for basic activities of daily living disability: Findings from the AGES project. $B M C$ Geriatrics, 17(1), 183.

Schnittker, J. (2007). Working more and feeling better: Women's health, employment, and family life, 19742004. American Sociological Review, 72(2), 221-238. 
Shergold, I. (2019). Taking part in activities, an exploration of the role of discretionary travel in older people's wellbeing. Journal of Transport \& Health, 12, 195-205.

Shim, H., Ailshire, J., Zelinski, E., \& Crimmins, E. (2018). The health and retirement study: Analysis of associations between use of the internet for health information and use of health services at multiple time points. Journal of Medical Internet Research, 20(5), e200.

Stanley, J. K., Hensher, D. A., Stanley, J. R., \& Vella-Brodrick, D. (2011). Mobility, social exclusion and well-being: Exploring the links. Transportation Research Part A: Policy and Practice, 45(8), 789-801.

Tang, N. K., Fiecas, M., Afolalu, E. F., \& Wolke, D. (2017). Changes in sleep duration, quality, and medication use are prospectively associated with health and well-being: Analysis of the UK household longitudinal study. Sleep, 40(3), 079.

Timmins, N. (2013). The four UK health systems: Learning from each other. King's Fund.

Toma, A., Hamer, M., \& Shankar, A. (2015). Associations between neighborhood perceptions and mental well-being among older adults. Health \& Place, 34(1), 46-53.

Tomaszewski, W. (2013). Living environment, social participation and wellbeing in older age: the relevance of housing and local area disadvantage. Journal of Population Ageing, 6(1-2), 119-156.

Vargas-Silva, C. and Rienzo, C., 2019. Briefing-Migrants in the UK: An Overview. The Migration Observatory at the University of Oxford. Available online at: http://tiny.cc/omnvhz. Accessed 19 Dec 2019

Victor, C. R., \& Scharf, T. (2005). Social isolation and loneliness. Understanding quality of life in old age. Open University Press, Buckingham, 100-16.

Waddell, G., \& Burton, A. K. (2006). Is work good for your health and well-being?. The Stationery Office.

Walker, R. B., \& HilleR, J. E. (2007). Places and health: A qualitative study to explore how older women living alone perceive the social and physical dimensions of their neighbourhoods. Social Science \& Medicine, 65(6), 1154-1165.

Walkner, T. J., Weare, A. M., \& Tully, M. (2018). You get old. You get invisible: Social isolation and the challenge of communicating with aging women. Journal of Women \& Aging, 30(5), 399.

Ware, J. E., Kosinski, M., \& Keller, S. D. (1998). SF-12: how to score the SF-12 physical and mental health summary scales. Quality Metric Inc. \& the Health Assessment Lab.

Weissman, J. D., \& Russell, D. (2018). Relationships Between Living Arrangements and Health Status Among Older Adults in the United States, 2009-2014: Findings from the National Health Interview Survey. Journal of Applied Gerontology, 37(1), 7-25.

World Health Organization. (2015). World report on ageing and health. World Health Organization.

Zali, M., Farhadi, A., Soleimanifar, M., Allameh, H., \& Janani, L. (2017). Loneliness, fear of falling, and quality of life in community-dwelling older women who live alone and live with others. Educational Gerontology, 43(11), 582-588.

Publisher's Note Springer Nature remains neutral with regard to jurisdictional claims in published maps and institutional affiliations. 